\title{
In-Hive Behavior of Pollen Foragers (Apis mellifera) in Honey Bee Colonies Under Conditions of High and Low Pollen Need
}

\author{
Anja Weidenmüller \& Jürgen Tautz \\ Lehrstuhl für Verhaltensphysiologie und Soziobiologie, Würzburg
}

\begin{abstract}
Pollen collection in honey bees is regulated around a homeostatic set-point. How the control of pollen collection is achieved is still unclear. Different feedback mechanisms have been proposed but little is known about the experience of pollen foragers in the hive. A detailed documentation of the behavior of pollen foragers in the hive under different pollen need conditions is presented here. Taking a broad observational approach, we analyze the behavior of individual pollen foragers in the hive between collecting trips and quantify the different variables constituting the in-hive stay. Comparing data from two colonies and 143 individuals during experimentally induced times of low vs. times of high pollen need, we show that individual foragers modulate their in-hive working tempo according to the actual pollen need of the colony: pollen foragers slowed down and stayed in the hive longer when pollen need was low and spent less time in the hive between foraging trips when pollen need by their colony was high. Furthermore, our data show a significant change in the trophallactic experience of pollen foragers with changing pollen need conditions of their colony. Pollen foragers had more short $(<3 \mathrm{~s})$ trophallactic contacts when pollen need was high, resulting in an increase of total number of trophallactic contacts. Thus, our results support the hypothesis that trophallactic experience is one of the various information pathways used by pollen foragers to assess their colony's pollen need.
\end{abstract}

Corresponding author: Anja Weidenmülller, Lehrstuhl für Verhaltensphysiologie und Soziobiologie, Biozentrum, Am Hubland, D-97074 Würzburg, Germany. E-mail: weiden@biozentrum.uni-wuerzburg.de

\section{Introduction}

Honey bees collect pollen to satisfy the protein requirements of their colony. Pollen is converted into proteinaceous brood food by nurse bees (Crailsheim et al. 1992) and is crucial for the brood production of a colony (Allen \& Jeffree 1956; Imdorf et al. 1998; Kunert \& Crailsheim 1988; Morton 1950). It is not collected by 
the nurse bees, which ultimately make use of it in the hive, but by the forager bees. Thus, there exists a division of labor between bees that work outside the hive, collecting pollen, and bees that work inside the hive, consuming it (reviewed in Seeley 1995).

Pollen foraging in honey bees is an example of a collective behavior that is precisely organized and carefully regulated. The pollen need of a colony is closely correlated with the relative amounts of larval brood and stored pollen present in the hive (for review see Dreller \& Tarpy 2000). If the number of cells containing larvae is high and the number containing pollen is low, then the colony's need for pollen is high. Colonies adjust their pollen foraging effort in accordance with the pollen need (Free 1967; Jeffree \& Allen 1957; Fewell \& Winston 1992) and try to maintain about $1 \mathrm{~kg}$ of stored pollen at any given time (Jeffree \& Allen 1957). This regulation of pollen storage around a homeostatic set-point provides the colony with a modest buffer against external fluctuations in pollen supply and ensures sufficient storage space for nectar to secure winter survival.

The mechanisms by which pollen foragers assess their colony's pollen need are not well understood. Two classes of models have been proposed. According to the direct assessment models, each pollen forager makes decisions based on her own direct experience of colony need (Pankiw et al. 1998; Vaughan \& Calderone 1998; Dreller et al. 1999; Dreller \& Tarpy 2000). Unlike nectar foragers, which unload their nectar to receiver bees just inside the hive entrance (Seeley 1995) pollen foragers enter deep into the hive and unload their pollen directly into pollen storage cells (Winston 1987). As they do so, they probably come across pollen and brood areas; hence, in principle, they have the possibility to directly assess their colony's pollen needs. The indirect assessment model proposes that foragers assess their colony's pollen need through cues transmitted by trophallactic interactions with hivemates. According to the model, nurse bees feed more of their proteinaceous brood food to adult bees when pollen stores are abundant and pollen foraging behavior is inhibited by consumption of proteinaceous food (Camazine 1993; see also Seeley 1995).

Surprisingly few details are known about the behavior of pollen foragers in the hive between foraging trips. For nectar foragers and for water foragers, detailed descriptions of in-hive experiences and changes in variables constituting these experiences have provided insights into feedback cues influencing the behavior of the individual (Lindauer 1952; Seeley et al. 1996; Kühnholz \& Seeley 1997). In contrast, we do not know which variables constitute the in-hive experience of returning pollen foragers and how these variables change following a change in the colony's pollen need.

In this paper, we provide detailed observational data on the behavior and experience of individual pollen foragers in the hive between foraging trips and quantify the parameters constituting an in-hive stay under different pollen need conditions. We discuss our results in light of the different feedback mechanisms proposed for the control of pollen collection, focusing on those 
variables that change with pollen need and thus present potential indicators of this need.

\section{Methods}

\section{Study Site and Colonies}

Experiments were conducted at the bee laboratory of the University of Würzburg in Aug. 1998. Two colonies headed by naturally mated Apis mellifera carnica queens were established in three-frame observation hives and housed inside a building. Each colony consisted of about 5000 bees. The bees could forage freely via a $30-\mathrm{cm}$ Plexiglas tunnel connecting the lowest frame to the outside. The hive entrances faced the same direction and were positioned $3 \mathrm{~m}$ apart. The colonies were set up $4 \mathrm{wks}$ before the experiments started and were matched for amounts of brood, honey, and stored pollen. Each colony had two frames containing brood and honey, while the contents of the third (uppermost) frame varied with each experiment, as described below.

\section{Manipulation of Pollen Need}

Before pollen stores were manipulated, the top frame in both colonies contained a mixture of brood and pollen. On the first day of the experiment, data on the behavior of pollen foragers in the unmanipulated colonies were collected. On subsequent days, the pollen need was manipulated twice in each colony and observations were repeated. Manipulations of pollen need were performed in the evenings. We experimentally induced the condition of high pollen need by replacing the top frame with one containing only uncapped brood (no pollen) and the condition of low pollen need by replacing it with one containing only pollen (no brood). Pollen and brood frames were derived from a colony not used in the experiment; they were matched for the size of the comb containing brood or pollen and for number of empty cells. To control for external effects (e.g. changes in pollen supply) on pollen forager behavior, manipulations were performed simultaneously and oppositely in the two observation colonies: while one colony's pollen need was increased, the other colony's pollen need was simultaneously decreased. The experiment lasted $7 \mathrm{~d}$, data were collected every day except on day 4 because of poor weather conditions resulting in very low foraging activity. Colony 1 received a comb of pollen on the evening of the first day and a comb of uncapped brood on the evening of the fifth day. Colony 2 received a comb of uncapped brood on the evening of the first day and a comb of pollen on the evening of the fifth day (see Table 1). Note that in the following, data from low pollen need conditions are always presented before data from high pollen need conditions; (thus in reversed order of the experimental procedure for colony 2). 
Table 1: Pollen need conditions (low vs. high) experienced by the two observation colonies. Arrows denote manipulation of pollen need. During the first day of observation, pollen need was not manipulated; the colonies then received opposed treatments twice. No data were taken on the fourth day

\begin{tabular}{|c|c|c|c|c|c|c|c|c|}
\hline Day & $\downarrow$ & 2 & 3 & 4 & 5 & $\downarrow$ & 6 & 7 \\
\hline Colony 1 & No manip. & Low & Low & No data & Low & & High & High \\
\hline Colony 2 & No manip. & High & High & No data & High & & Low & Low \\
\hline
\end{tabular}

\section{Data Collection}

Returning pollen foragers were captured at the hive entrance and labeled with numbered plastic tags (Opalithplättchen) the day before observations started. A total of 80 pollen foragers were individually marked in each colony. Observations started at $0800 \mathrm{~h}$ and ended at $1300 \mathrm{~h}$, when the number of returning pollen foragers fell below one per min.

Pollen foragers in the two colonies were observed simultaneously by two observers that switched between the colonies every hour to minimize observational bias. A focal observation started when the forager entered the hive and ended either when the bee exited for her next collecting trip or when she stayed in the hive longer than $15 \mathrm{~min}$. The 15-min level was chosen in order to record data from many individuals and avoid long observation of bees which had stopped foraging. Observations were recorded using a laptop computer equipped with software for behavioral data capture and analysis (Observer, Noldus, The Netherlands). From these records, we calculated the following variables: (1) the latency for each behavior relative to when a bee entered the hive (time to inspecting the first cell, time to unloading pollen, time to first trophallactic contact and time to leaving the hive); (2) the times of inspecting the first cell to unloading pollen and of unloading pollen to leaving the hive; (3) the number of cells inspected; (4) the number of waggle dance circuits performed; (5) the number of waggle dance circuits followed; (6) the number and duration of all trophallactic contacts. During a trophallactic contact the recipient bee puts her tongue between the mandibles of a donor bee and receives liquid food. Trophallactic contacts were classified as 'short' when they lasted less than $3 \mathrm{~s}$ and as 'long' when they lasted 3 s or more (Kühnholz \& Seeley 1997; Crailsheim 1998).

After the bee had departed, or $15 \mathrm{~min}$ had elapsed without departure, the observer closely watched the entrance tunnel for the next labeled pollen forager, which was then followed on her passage through the hive. During all observations, foraging activity was measured every hour by counting over 5 min the returning pollen and non-pollen foragers in the Plexiglas entrance tunnel while they were walking in.

\section{Statistical Analysis}

Unless noted otherwise, values are given as mean \pm one standard error (SE). If a forager was recorded more than once during $1 \mathrm{~d}$, only the first set of observations on her was used for data analysis. Data for the days following each 
manipulation are pooled (days 2, 3, 5, and days 6, 7). Proportional data were compared using the $\chi^{2}$ test. Data on individual behavior were analysed using a two-way ANOVA with colony and pollen treatment as independent parameters. Data consisting of counts containing zero values were arcsinh transformed; counts without zero values and data showing skewed distributions (data on duration of trophallaxis) were log transformed before analysis (Fowler et al. 1998). The chosen level of significance was 0.05. Numerous parameters of individual behavior were analysed based on one data set, resulting in an increase of Type I error. Strict avoidance of Type I error would require Bonferroni adjustment of the $\alpha$ level for each test to 0.009 (11 parameters of individual in-hive behavior with a mean correlation coefficient of 0.29; Uitenbroek 1997). However, since such Bonferroni adjustment ignores our sampling of two independent colonies an $\alpha$ level of 0.009 is too conservative.

\section{Results}

\section{Colony Foraging Activity}

Colonies showed a clear response to our experimentally induced state of high or low pollen need. The number of foragers that returned to the hive with pollen increased significantly when a colony's pollen need was high and decreased significantly when it was low $(\mathrm{F}=5.40 ; \mathrm{p}<0.05$; Table 2$)$. There was, however, no significant effect of manipulation on the total number of foragers returning to the hive in $5 \mathrm{~min}(\mathrm{~F}=2.00 ; \mathrm{p}>0.1)$. Colonies did not significantly differ in number of pollen foragers $(\mathrm{F}=0.18 ; \mathrm{p}>0.6)$ or in total number of foragers $(\mathrm{F}=1.50 ; \mathrm{p}>0.2)$.

\section{Individual Behavioral Response}

We observed a total of 143 in-hive stays of returning pollen foragers. These bees showed a characteristic sequence of actions. In general, it consisted of selfgrooming followed by inspecting cells and eventually unloading pollen into the last cell inspected. The sequence then continued with additional self-grooming, receiving food and finally departing for the next foraging trip. Rarely, the foragers groomed themselves extensively after unloading once and then unloaded into a second and sometimes even a third cell. Bees that showed this behavioral pattern always stayed in the hive longer than $15 \mathrm{~min}$ and presumably had stopped pollen foraging for the day. Most trophallactic contacts (receiving food) occurred after a pollen forager had unloaded her pollen.

\section{Recruitment Communication}

Table 2 shows that only a small percentage of pollen foragers produce waggle dances: of 143 pollen foragers, only 16 danced (11.2\%). The probability of waggle 


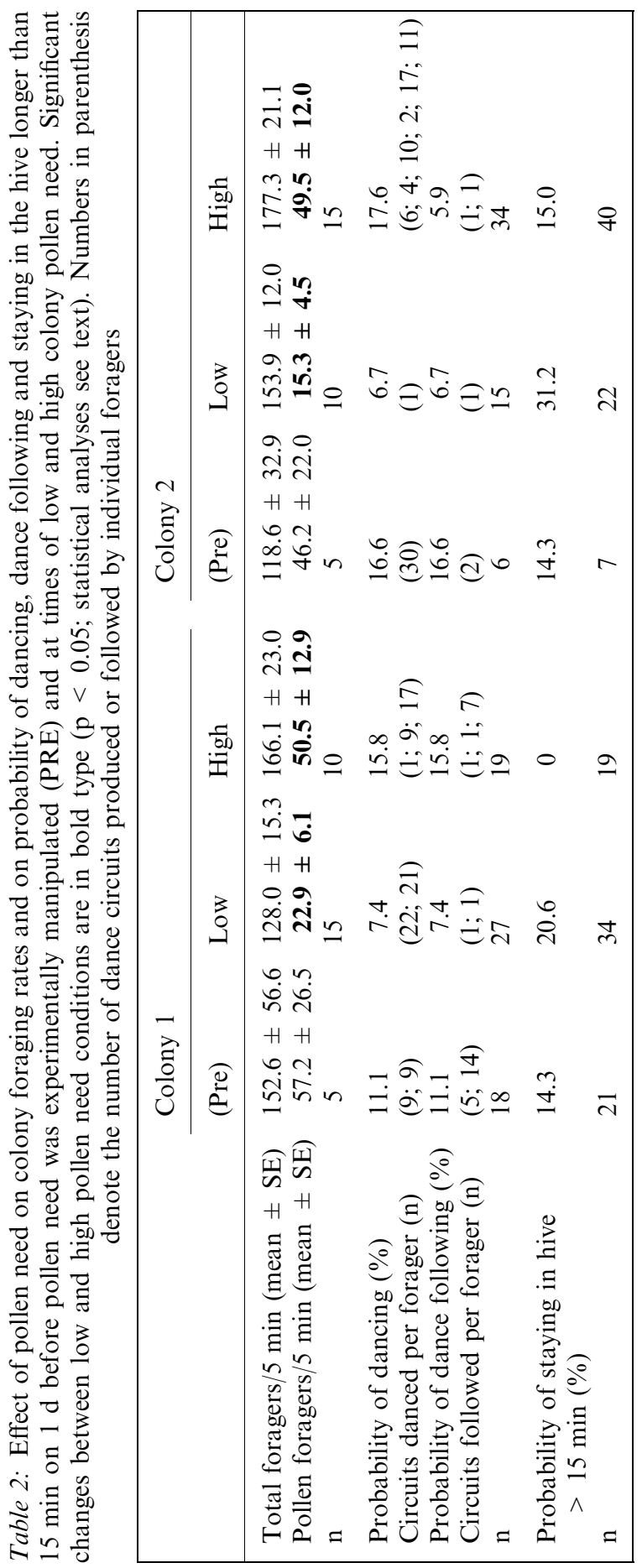


dancing did not significantly differ between times of low and high pollen need (colony $1, \mathrm{p}>0.6$; colony $2, \mathrm{p}>0.5$; Yates corrected $\chi^{2}$ ). However, there seems to be a trend towards a greater dance probability when pollen need is high.

Similarly, only 12 of the 143 pollen foragers followed waggle dances $(8.9 \%)$. Never were these individuals themselves dancers. There was no significant change in the probability of dance following with different pollen need conditions (colony $1, \mathrm{p}>0.6$; colony 2, $\mathrm{p}>0.5$; Yates corrected $\chi^{2}$ ).

The number of dance circuits followed or produced per dance varied between bees and showed no clear change with pollen need (Table 2).

\section{Time Budgets}

In order to obtain data from a large number of bees, observations on individual pollen foragers were ended if the bee had not left the hive 15 min after having entered it. The proportion of foragers that stayed in the hive longer than 15 min showed a tendency to decrease with pollen need in one colony (colony 1, $\mathrm{p}<0.08$; colony 2, $\mathrm{p}>0.3$; Yates corrected $\chi^{2}$; Table 2). These bees might have either abandoned pollen foraging, and thus would represent a subgroup within the observed foragers, or just slowed down considerably. Because our observational method did not allow us to distinguish between these two cases, data from these bees were not pooled with data from bees that left the hive again within our observation period.

Pollen foragers spent significantly less time in the hive between collecting trips when pollen need was high compared to when it was low $(\mathrm{F}=8.11$, $\mathrm{p}<0.01$; Fig. 1). The in-hive stay of pollen foragers consists of several phases of different duration. Table 3 shows the data for each phase of the in-hive stay. The time from entering the hive to inspecting the first cell significantly changed with pollen need: pollen foragers spent significantly less time until inspecting the first cell when pollen need was high than when it was low $(\mathrm{F}=5.69, \mathrm{p}<0.05)$. When

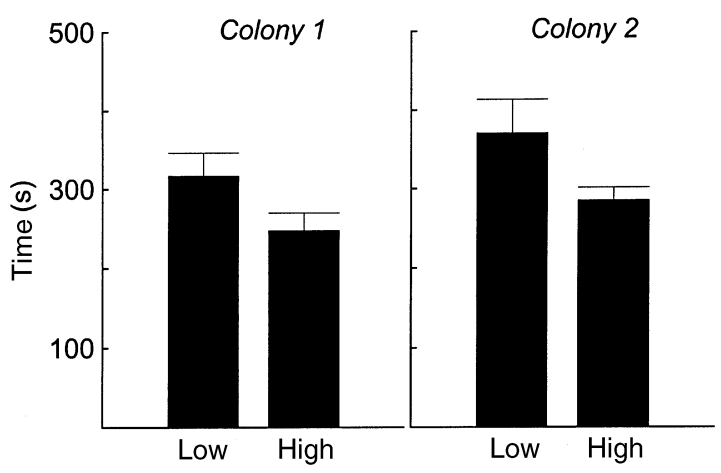

Fig. 1: Effect of pollen need (low vs. high) on the time pollen foragers spent in the hive (mean \pm SE) between foraging trips. Pollen foragers spent significantly more time in the hive when pollen need of their colony was low compared with when it was high $(\mathrm{F}=8.11, \mathrm{p}<0.01$; two-way ANOvA $)$ 


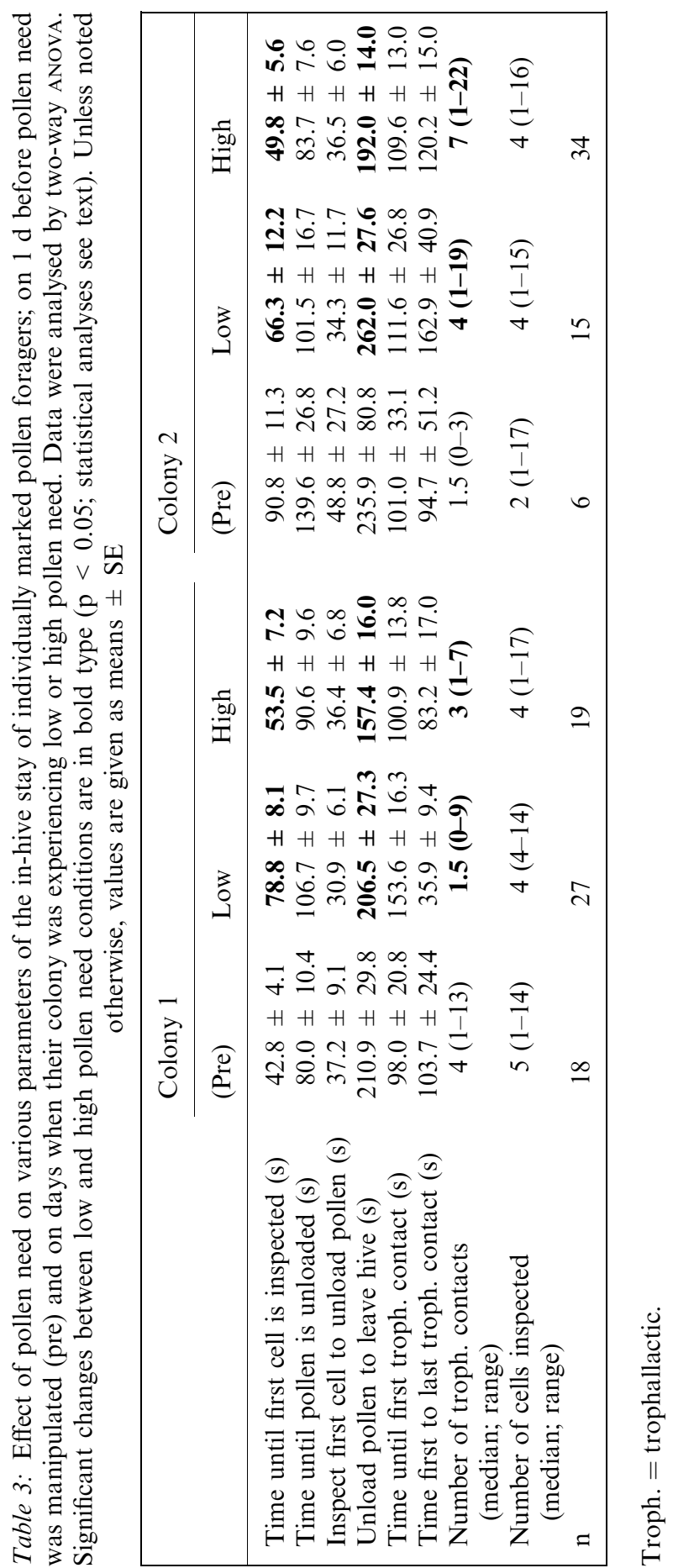


pollen need was low, the pollen foragers spent considerable time grooming and walking around slowly before inspecting the first cell. Pollen foragers also showed a change in the last phase of their in-hive stay: they stayed in the hive significantly longer after having unloaded pollen when pollen need was low than when it was high $(\mathrm{F}=6.30, \mathrm{p}<0.05)$.

The time spent on cell inspection (time from inspecting the first cell to unloading pollen into a cell) did not significantly differ between times of high and low pollen need $(\mathrm{F}=0.28, \mathrm{p}>0.5$; Table 3$)$. Similarly, the time spent between entering the hive and unloading pollen showed no significant change with pollen need $(\mathrm{F}=2.54, \mathrm{p}>0.1)$. Time budgets for trophallactic behavior are presented below.

Under tight statistical control for Type I error (see methods) only the change in total time spent in the hive remains significant, while changes in the time spent until inspecting the first cell and the time spent in the hive after having unloaded pollen represent trends.

Colonies did not significantly differ in any of the above parameters (time in hive, $\mathrm{F}=2.82, \mathrm{p}>0.1$; latency to inspecting cell, $\mathrm{F}=0.76, \mathrm{p}>0.3$; time from inspecting cell to unloading pollen, $\mathrm{F}=0.06, \mathrm{p}>0.8$; latency to unloading pollen, $\mathrm{F}=0.32, \mathrm{p}>0.5)$ except in the time the foragers spent in the hive after unloading pollen $(\mathrm{F}=4.59, \mathrm{p}<0.05)$.

In summary, we found a clear adjustment of the working tempo of pollen foragers depending on the pollen need of their colony. The longer in-hive stay of pollen foragers under low pollen need was largely caused by a delayed inspection of cells before unloading and by a prolonged stay in the hive after unloading.

\section{Inspection of Cells}

The number of cells inspected before unloading pollen was not significantly influenced by pollen need $(\mathrm{F}=0.33, \mathrm{p}>0.5$; Table 3$)$ and did not significantly differ between colonies $(\mathrm{F}=0.06, \mathrm{p}>0.8)$. A pollen forager inspected between one and 17 cells; pollen was usually unloaded after the forager had inspected between two and five cells.

\section{Trophallaxis}

The time between entering the hive and the first trophallactic contact did not significantly differ between times of high and low pollen need $(\mathrm{F}=2.45, \mathrm{p}>0.1$; Table 3). The time between first and last trophallactic contacts also did not significantly change with pollen need $(\mathrm{F}=0.01, \mathrm{p}>0.9$; Table 3$)$.

By far, most of the trophallactic contacts observed were receiving contacts (625 of 633). Trophallactic contacts were usually terminated by the pollen forager who withdrew her tongue while the donor bee was standing still with spread mandibles.

A pollen forager made between 0 and 22 trophallactic contacts per in-hive stay. The number of contacts a pollen forager made varied considerably between 

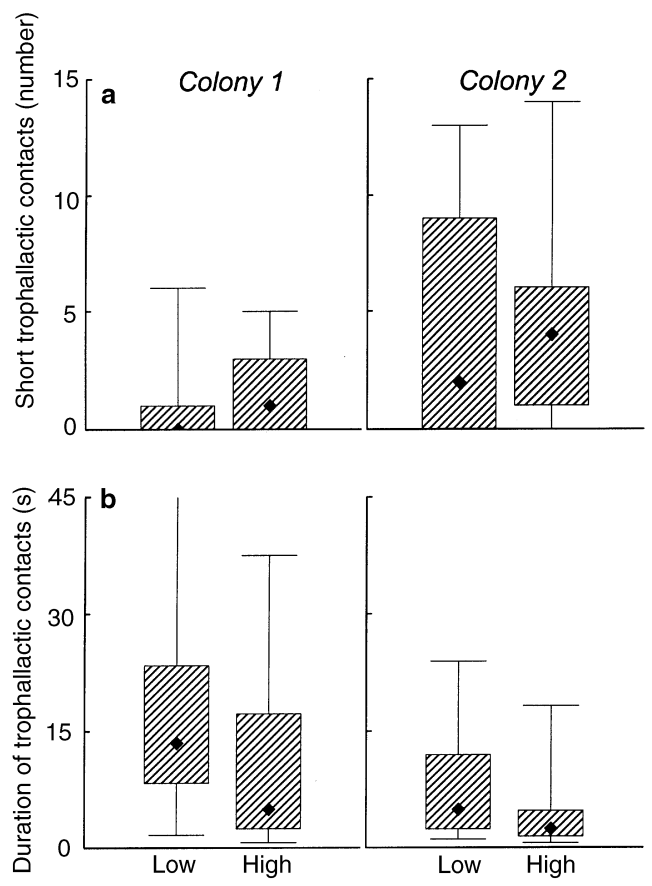

Fig. 2: Trophallactic experience of pollen foragers during their stay in the hive under different pollen need conditions. (a) Pollen foragers experienced significantly more short $(<3$ s) trophallactic receiving contacts when pollen need of their colony was high compared with when it was low $(\mathrm{F}=5.02$, $\mathrm{p}<0.05$; two-way ANOvA; data arcsinh transformed). (b) Trophallactic contacts were, in general, significantly shorter when pollen need of the colony was high $(\mathrm{F}=9.73, \mathrm{p}<0.01$; two-way ANOvA; data $\log$ transformed). $\diamond$ median; boxes, quartile range; lines, range. Note that for colony 1 the maximum duration of trophallactic contacts under low pollen need (69 s) is not shown

individuals and changed with colony pollen need: pollen foragers had more trophallactic contacts when pollen need was high than when it was low $(F=4.00$, $\mathrm{p}<0.05$; Table 3 ). This was caused by a change in the number of short contacts. While the number of long trophallactic contacts did not differ between times of low and high pollen need $(\mathrm{F}=0.06, \mathrm{p}>0.8)$, the number of short contacts was significantly higher when pollen need was high $(\mathrm{F}=5.02, \mathrm{p}<0.05$; Fig. 2a).

Trophallactic contacts varied considerably in duration, ranging from 0.1 to $69 \mathrm{~s}$. The median duration of the 625 receiving contacts was $2.8 \mathrm{~s}$ (mean $6.5 \mathrm{~s}$ ). The median duration of trophallactic contacts a pollen forager made changed with pollen need. When colony pollen need was high, trophallactic contacts were short compared to pollen need was low $(\mathrm{F}=9.73$, $\mathrm{p}<0.01$; Fig. $2 \mathrm{~b})$.

Under tight statistical control for Type I error (see methods) only the change in duration of trophallactic contacts remains significant, while changes in the total number of trophallactic contacts and the number of short contacts represent trends. 
Thus, we found a clear change in trophallactic experience of pollen foragers between times of low vs. times of high pollen need. Trophallactic contacts were significantly shorter when pollen need was high than when it was low. Pollen foragers had more trophallactic contacts when pollen need was high, caused by an increase in short trophallactic contacts.

Colonies significantly differed in most parameters of trophallactic experience of their pollen foragers. In colony 2, which went from high to low pollen need, pollen foragers had more trophallactic contacts $(\mathrm{F}=24.05, \mathrm{p}<0.001)$, more short contacts $(\mathrm{F}=18.71, \mathrm{p}<0.001)$ and contacts in general were shorter $(\mathrm{F}=10.93 ; \mathrm{p}<0.001)$ than in colony 1 . Furthermore, pollen foragers in colony 2 spent significantly more time between first and last contact $(\mathrm{F}=14.44$; $\mathrm{p}<0.001)$ than pollen foragers in colony 1 .

We found no significant interaction between colony and pollen treatment effects in any of the statistical comparisons $(\mathrm{p} \geq 0.1)$.

\section{Discussion}

The control of pollen foraging in a honey bee colony is one of many fascinating examples of functional flexibility in social insect societies. Understanding how this colony-level flexibility is implemented at the level of individual worker bees is crucial for a thorough understanding of how collective control is achieved.

How do honey bee workers obtain information about the pollen need of their colony and how do they then modulate their behavior accordingly? Our study adds to the understanding of this process by presenting a detailed description of the in-hive behavior of pollen foragers between foraging trips. We found significant differences in the trophallactic experience of pollen foragers between times of low and high pollen need. Thus, our results provide indirect support for the hypothesis that trophallaxis is an important information pathway, providing foragers with information about the pollen need of their colony. We also showed that foragers modulate their behavior in response to changing pollen need by adjusting their working tempo in the hive.

\section{Reaction to Changes in Pollen Need}

The ability of honey bee colonies to adjust their pollen influx to pollen need has been demonstrated numerous times (for review see Fewell \& Winston 1992). One way of adjusting pollen influx is changing the number of pollen foragers. Two factors influencing this number are the rates of recruitment for and abandonment from the task of pollen foraging (Seeley 1995). Our data on waggle dance behavior of the pollen foragers show that even when pollen need was extremely high, only a relatively small proportion (less than one fifth of the pollen foragers) performed waggle dances. The probability of performing waggle dances did not show a significant change with pollen need, however, there was a trend towards a greater likelihood of performing waggle dances when pollen need was high. This is 
in accordance with data by Camazine, who found an increase in dance probability when pollen need was high (reported in Seeley 1995).

Our study provides no data on abandonment rates. However, the number of pollen foragers that stayed in the hive longer than $15 \mathrm{~min}$ and probably abandoned pollen foraging showed a trend to decrease when pollen need was high.

In addition to changing the number of pollen foragers, a colony can modulate its pollen collection by changing the per capita work effort of pollen foragers. Pollen foragers can adjust trip time and pollen load size to adaptively tune the pollen collection rate of their colony (Fewell \& Winston 1992; Janmaat et al. 2000). Our data show that pollen foragers also modify the time spent inside the hive. When colony pollen need was high, pollen foragers left the hive only a few minutes after having entered it. When pollen need was low the pollen foragers spent much more time in the hive between foraging trips. This change in mean time budgets has been reported before, based on arrival and departure data of pollen foragers at the hive entrance (Fewell \& Winston 1992). Our data however, present a more detailed picture of what is actually happening in the hive. In particular, these data reveal when during their stay the pollen foragers slow down.

The in-hive stay of pollen foragers consists of several phases. A change in time budget occurred during the first phase of the in-hive stay, namely the time from entering the hive to inspecting the first cell. Pollen foragers spent more time in this phase when pollen need was low than when it was high. Note that our manipulations of pollen need were performed by replacing the top frame and that both the pollen and brood frames used for manipulation of pollen need contained only few empty cells. Therefore, the bees that we observed, which walked mainly on the lower two combs, encountered a comb area that had not changed in number of empty cells compared to when pollen need was high, and so were not experiencing greater difficulty in finding an appropriate location for inspecting cells. Rather, the reason for the increase in time was that they entered the hive walking rather than running and spent more time grooming and walking around slowly before inspecting a cell. Furthermore, the pollen foragers also slowed down in the last phase of their in-hive stay, the time from unloading their pollen to leaving the hive for the next foraging trip. Thus, we are confident that the pollen foragers actually modified their working speed and were not in some way experiencing difficulties that restricted them.

Why do pollen foragers not always work at a high rate? 'Slow' individuals may serve their colony in two ways: First, they probably save energy. Increased work effort may increase the rate of physical deterioration (Neukirch 1982). Perhaps only when pollen is immediately and urgently needed by the colony does it pay for an individual to bear the higher costs of increased foraging effort (Eckert et al. 1994). Second, in staying in the hive longer, pollen foragers are probably available for other more urgent tasks, thus providing a reserve of labor. 


\section{Perception of Changes in Pollen Need}

The adjustments of working speed at the individual level (Fig. 1) and the rate of returning pollen foragers at the colony level (Table 2) shows that the bees sensed our manipulation of pollen need. How did they obtain the information that pollen need had changed? Several cues have been suggested as potentially providing pollen foragers with information about pollen need. The time spent until finding an appropriate cell for unloading pollen has been suggested as one such possible cue (Dreller \& Tarpy 2000). For nectar foragers it is well documented that the time spent searching for a receiver bee in the hive influences their foraging and recruiting decisions (Seeley 1989; Seeley \& Tovey 1994). Thus, it may be tempting to think that pollen collection is controlled by a similar feedback mechanism. However, as discussed above, our data suggest that, at least under the experimental conditions we examined, the time spent until finding an appropriate cell cannot serve as a reliable cue for pollen foragers, since changes in times resulted from a self-controlled change in the bees' behavior rather than being imposed on the bees' by changes in the hive environment.

The idea that under low pollen need the pollen foragers were not experiencing difficulties in finding cells for unloading their pollen is further supported by the fact that pollen foragers in our experiment sampled a constant number of cells during a constant amount of time independent of pollen need. The number of cells a pollen forager must inspect before unloading her pollen is a second variable that has been suggested as potentially providing information about colony pollen need (Dreller \& Tarpy 2000). The fact that pollen foragers in our experiment did not use this information pathway does not rule out the possibility that under different conditions a change in the ratio of empty cells to full cells (pollen or brood) can provide information about a change in pollen need. Camazine (reported in Seeley 1995), in manipulating the pollen need of a colony, changed the ratio of pollen cells to empty cells in the part of the hive encountered by the pollen foragers (providing either a comb of empty cells or a comb of pollen in the lowest position). He found an increase in the number of cells inspected when the empty frame was added.

How exactly bees could obtain information by inspecting cells is unclear. One possibility is that the bees look for an appropriate (empty) cell for unloading pollen and count the number of 'inappropriate' (full pollen) cells while doing so. In this scenario, pollen foragers would have to estimate the amounts of brood and pollen separately to obtain information about the colony's pollen need. Inspecting cells might, however, provide the bees with information in a different way. Sampling a certain number of cells might inform bees about the ratio of cells with and without pollen or provide information about the type and quality of pollen stored in the colony. We observed that many of the cells inspected contained some pollen but were far from being 'full'. Indeed, often a pollen forager under investigation would inspect a cell the previous pollen forager had just unloaded their pollen into and would continue inspecting other cells. To clarify whether 
pollen foragers are simply looking for empty cells, as has been suggested, or whether they are collecting some other information while inspecting cells we need data on what kind of cells pollen foragers inspect and what makes a cell 'appropriate' for receiving pollen.

After unloading their pollen loads, the pollen foragers made numerous trophallactic contacts. More than $50 \%$ of the trophallactic interactions lasted no longer than $3 \mathrm{~s}$. During such short contacts no food transfer takes place (Korst \& Velthuis 1982). However, they are probably sufficiently long for the pollen forager to find out whether the donor bee will provide food and if so what kind of food. The trophallactic experience of the pollen foragers changed with their colony's pollen need. This is the strongest change in the parameters measured besides the changes in time budgets discussed above. Why does trophallactic experience change and how could information about pollen need be encoded in this experience?

Camazine (1993) demonstrated that trophallactic contacts between pollen foragers and bees on the brood nest are sufficient to induce a decrease in pollen foraging when pollen stores are experimentally increased. Obviously, pollen collection was inhibited through a cue received by the pollen foragers via trophallaxis. Camazine explained this phenomenon by hypothesizing a change in the trophallactic behavior of nurse bees: when a colony has ample pollen reserves nurse bees will feed more proteinaceous brood food to adult bees than when the colony is in need of pollen. Thus, under low pollen need conditions, protein is widely dispensed throughout the colony via trophallaxis and inhibits pollen foraging. Several studies provide support for this indirectinhibitor hypothesis: (1) the transfer of protein from nurse bees to other hive mates, including foragers, has been indirectly demonstrated using radioactively labeled protein (Crailsheim 1991; Crailsheim et al. 1992); (2) proteinaceous food transfer to foragers increases when pollen reserves are large (Camazine et al. 1998).

However, nothing was known about the actual trophallactic experience of pollen foragers in the hive and it remained unclear precisely which parameter of the trophallactic experience could encode information about pollen need. Various alternatives have been proposed: the quality or amount of protein received per in-hive stay and/or the ease of finding a protein dispensing trophallaxis partner could change with pollen need (Camazine et al. 1998).

Our study demonstrated that the trophallactic contacts a pollen forager made were consistently shorter when pollen need was high compared to when it was low. This supports the notion that the amount of protein received by a pollen forager per in-hive stay changes with the pollen need of the colony: as the colony need for pollen increases, nurse bees have less excess proteinaceous food, pollen foragers therefore receive less protein per trophallactic contact and thus experience protein hunger. Pollen foragers experienced a strong increase in the number of short and presumably unsuccessful contacts when their colony experienced pollen need. These findings support the idea that, compared to conditions of low pollen need, when it is easy to locate hive bees that are 
willing and able to transfer large amounts of proteinaceous food, pollen foragers have to sample more hive bees in order to find a protein-dispensing bee when the pollen need of their colony increases. This would imply an active search for protein on the part of 'protein-hungry' pollen foragers and not merely the perception of protein as a byproduct of trophallaxis as originally proposed by Camazine (1993). Foraging aged bees have a considerable protein turnover rate (Crailsheim 1986) but their capability to digest pollen is limited (Moritz \& Crailsheim 1987; Szolderits \& Crailsheim 1993). They therefore rely on liquid proteinaceous food received from hive mates to fulfill their protein requirements (for a review see Crailsheim 1998). The idea that pollen foragers experience protein hunger and actively search for protein dispensing trophallactic partners when the pollen need of their colony increases is further supported by the fact that a greater proportion of pollen foragers are found in the brood nest, where they are more likely to encounter nurse bees, when pollen need is high compared with when it is low (Camazine et al. 1998).

Perception of pollen hunger might play an important role in 'switching on' pollen collection. A comparable indirect feedback mechanism is described for the control of water collection, where foragers start collecting water when they are thirsty (Lindauer 1954; Kiechle 1961).

There is increasing evidence that the behavior of pollen foragers is influenced not only by indirect cues (Camazine 1993) but also by direct cues (Pankiw et al. 1998; Vaughan \& Calderone 1998; Dreller et al. 1999; Dreller \& Tarpy 2000). Workers in insect societies often use more than one information pathway to increase the reliability of information (Franks 1999), and the two classes of models discussed for the control of pollen collection are not necessarily mutually exclusive. Several cues, direct and indirect, may be used by pollen foragers to adjust their foraging behavior according to their colony's need. The information sources used may differ depending on whether a colony needs to decrease or increase its pollen collection and whether this change has to be small or large. While protein hunger is probably important in starting pollen collection, direct cues may play an important role in shutting down pollen collection.

In summary, our study shows that pollen foragers adjust their working speed in the hive to the pollen need of their colony: when pollen need is high they spend less time in the hive between foraging trips. The trophallactic experience changes with pollen need. Even though pollen foragers spend less time in the hive when pollen need is high, they experience more short contacts compared with low pollen need conditions. These findings support the hypothesis that protein hunger is one possible information pathway informing pollen foragers about the pollen need of their colony. In order to reveal the relative importance of the different trophallactic parameters, experiments aimed at testing directly the influence of trophallactic interaction rates and protein transfer on pollen foraging behavior are needed. The adaptive control of pollen collection in honey bees still has many mysteries to be solved. 


\section{Acknowledgements}

We sincerely thank Anja Hickelsberger for her help with collecting data. Christoph Kleineindam, Tom Seeley, Corinna Thom and two anonymous reviewers provided helpful comments on the manuscript. This work was supported by the DFG-Sonderforschungsbereich 554 ('Arthropod Behavior').

\section{Literature Cited}

Allen, M. D. \& Jeffree, E. P. 1956: The influence of stored pollen and colony size on the brood rearing of honey bees. Ann. Appl. Biol. 44, 649-656.

Camazine, S. 1993: The regulation of pollen collection by honey bees: how foragers assess the colony's need for pollen. Behav. Ecol. Sociobiol. 32, 265-272.

Camazine, S., Crailsheim, K., Hrassnigg, N., Robinson, G. E., Leonhard, B. \& Kropiunigg, H. 1998: Protein trophallaxis and the regulation of pollen foraging by the honey bees (Apis mellifera L.). Apidologie 29, 113-126.

Crailsheim, K. 1986: Dependence of protein metabolism on age and season in the honeybee (Apis mellifera carnica Pollm.). J. Insect. Physiol. 32, 629-634.

Crailsheim, K., 1991: Interadult feeding of jelly in honeybee (Apis mellifera L.) colonies. J. Comp. Physiol. B 161, 55-60.

Crailsheim, K. 1998: Trophallactic interactions in the adult honeybee (Apis mellifera L.). Apidologie 29, 97-112.

Crailsheim, K., Schneider, L. H. W., Hrassnigg, N., Bühlmann, G., Brosch, U., Gmeinbauer, R. \& Schöffmann, B. 1992: Pollen consumption and utilization in worker honeybees (Apis mellifera carnica): dependence on individual age and function. J. Insect Physiol. 38, 409-419.

Dreller, C., Page, R. E. \& Fondrk, M. K. 1999: Regulation of pollen foraging in honeybee colonies: effects of young brood, stored pollen, and empty space. Behav. Ecol. Sociobiol. 45, 227-233.

Dreller, C. \& Tarpy, D. R. 2000: Perception of the pollen need by foragers in a honeybee colony. Anim. Behav. 59, 91-96.

Eckert, C. D., Winston, M. L. \& Ydenberg, R. C. 1994: The relationship between population size, amount of brood, and individual foraging behaviour in the honey bee, Apis mellifera $\mathrm{L}$. Oecologia 97, $248-255$.

Fewell, J. H. \& Winston, M. L. 1992: Colony state and regulation of pollen foraging in the honey bee, Apis mellifera L. Behav. Ecol. Sociobiol. 30, 387-393.

Fowler, J., Cohen, L. \& Jarvis, P. 1998: Practical Statistics for Field Biology. John Wiley \& Sons, Chichester.

Franks, N. R. 1999: Information flow in the social domain: how individuals decide what to do next. In: Information Processing in Social Insects (Detrain, C., Deneubourg, J. L. \& Pasteels, J. M., eds). Birkhäuser-Verlag, Basel.

Free, J. B. 1967: Factors determining the collection of pollen by honeybee foragers. Anim. Behav. 15, $134-144$.

Imdorf, A., Rickli, M., Kilchenmann, V., Bogdanov, S. \& Wille, H. 1998: Nitrogen and mineral constituents of honey bee worker brood during pollen shortage. Apidologie 29, 315-325.

Janmaat, A. F., Winston, M. L. \& Ydenberg, R. C. 2000: Condition dependent response to changes in pollen stores by honey bee (Apis mellifera) colonies with different parasitic loads. Behav. Ecol. Sociobiol. 47, 171-179.

Jeffree, E. P. \& Allen, M. D. 1957: The annual cycle of pollen storage by honey bees. J. Econ. Entomol. 50, $211-212$.

Kiechle, H. 1961: Die soziale Regulation der Wassersammeltätigkeit im Bienenstaat und deren physiologische Grundlage. Z. Vergl. Physiol. 45, 154-192.

Korst, P. J. A. M. \& Velthuis, H. H. W. 1982: The nature of trophallaxis in honeybees. Insectes Soc. 29, 209-221.

Kühnholz, S. \& Seeley, T. D. 1997: The control of water collection in honey bee colonies. Behav. Ecol. Sociobiol. 41, 407-422.

Kunert, K. \& Crailsheim, K. 1988: Seasonal changes in carbohydrate, lipid and protein content in emerging worker honey bees and their mortality. J. Apic. Res. 27, 13-21. 
Lindauer, M. 1952: Ein Beitrag zur Frage der Arbeitsteilung im Bienenstaat. Z. Vergl. Physiol. 34, $299-345$.

Lindauer, M. 1954: Temperaturregulierung und Wasserhaushalt im Bienenstaat. Z. Vergl. Physiol. 36, $391-432$.

Moritz, B. \& Crailsheim, K. 1987: Physiology of protein digestion in the midgut of the honeybee (Apis mellifera L.). J. Insect Physiol. 33, 923-931.

Morton, K. 1950: The food of worker bees of different ages. Bee World 32, 78 - 79.

Neukirch, A. 1982: Dependence of life span of the honey bee (Apis mellifera) upon flight performance and energy consumption. J. Comp. Physiol. 146, 35- 40.

Pankiw, T., Page, R. E. \& Fondrk, M. K. 1998: Brood pheromone stimulates pollen foraging in honey bees (Apis mellifera). Behav. Ecol. Sociobiol. 44, 193-198.

Seeley, T. D. 1989: Social foraging in honey bees: how nectar foragers assess their colony's nutritional status. Behav. Ecol. Sociobiol. 24, 181-354.

Seeley, T. D. 1995: The Wisdom of the Hive: The Social Physiology of Honey Bee Colonies. Harvard Univ. Press, Cambridge.

Seeley, T. D., Kühnholz, S. \& Weidenmüller, A. 1996: The honey bee's tremble dance stimulates additional bees to function as nectar receivers. Behav. Ecol. Sociobiol. 39, 419-427.

Seeley, T. D. \& Tovey, C. A. 1994: Why search time to find a food-storer bee accurately indicates the relative rates of nectar collecting and nectar processing in honey bee colonies. Anim. Behav. 47, $311-316$

Szolderits, M. J. \& Crailsheim, K. 1993: A comparison of pollen consumption and digestion in honeybee (Apis mellifera carnica) drones and workers. J. Insect Physiol. 39, 877-881.

Uitenbroek, D. G., 1997: SISA Binomial. D. G. Uitenbroek, Southampton. http://home.clara.net/sisa/ binomial.htm.

Vaughan, A. M. \& Calderone, N. 1998: Regulation of pollen collection by honey bee colonies. In: 13th Congr. IUSSI. (Schwarz, M. P. \& Hogendoorn, K., eds). IUSSI, Adelaide.

Winston, M. L. 1987: The Biology of the Honey Bee. Harvard Univ. Press, Cambridge. 